Article

\title{
Dominant Effects of Short-Chain Branching on the Initial Stage of Nucleation and Formation of Tie Chains for Bimodal Polyethylene as Revealed by Molecular Dynamics Simulation
}

\author{
Yanling Hu ${ }^{1}$, Yunqi Shao ${ }^{1}$, Zhen Liu ${ }^{1}$, Xuelian $\mathrm{He}^{1, *}$ and Boping Liu ${ }^{2, *}$ \\ 1 Shanghai Key Laboratory of Multiphase Material Chemical Engineering, East China University of Science \\ and Technology, Shanghai 200237, China; huyl@mail.ecust.edu.cn (Y.H.); \\ yunqi_shao@mail.ecust.edu.cn (Y.S.); liuzhen@ecust.edu.cn (Z.L.) \\ 2 College of Materials and Energy, South China Agricultural University, Guangzhou 510642, China \\ * Correspondence: hexl@ecust.edu.cn (X.H.); boping@scau.edu.cn (B.L.)
}

Received: 9 October 2019; Accepted: 5 November 2019; Published: 8 November 2019

\begin{abstract}
The molecular mechanism of short-chain branching (SCB), especially the effects of methylene sequence length (MSL) and short-chain branching distribution (SCBD) on the initial stage of nucleation, the crystallization process, and particularly the tie chain formation process of bimodal polyethylene (BPE), were explored using molecular dynamics simulation. This work constructed two kinds of BPE models in accordance with commercial BPE pipe resins: SCB incorporated in the long chain or in the short chains. The initial stage of nucleation was determined by the MSL of the system, as the critical MSL for a branched chain to nucleate is about $60 \mathrm{CH}_{2}$. SCB incorporated in the long chain led to a delay of the initial stage of nucleation relative to the case of SCB incorporated in the short chains. The increase of branch length could accelerate the delay to nucleation. The location of short chain relative to the long chain depended on the MSL of the short chain. As the MSL of the system decreased, the crystallinity decreased, while the tie chains concentration increased. The tie chains concentration of the BPE model with branches incorporated in the long chain was higher than that with branches incorporated in the short chain.
\end{abstract}

Keywords: short-chain branching distribution; methylene sequence length; bimodal polyethylene; molecular dynamics simulation; crystal nucleation; tie chains

\section{Introduction}

Polyethylene (PE) is the most widespread thermoplastic used in various consumer goods as a result of its outstanding end-use properties and high performance-price ratio. Polymer chain microstructure, such as short-chain branching distribution (SCBD) and molecular weight distribution (MWD), can dominantly influence the properties of PE. Revealing the molecular mechanism of these chain microstructures evolution will be very important for the analysis of the relationship between polymer structure and polymer properties and also the development of high-performance polymer materials. For instance, due to the well-controlled SCBD and MWD, bimodal polyethylene (BPE) shows excellent mechanical properties and good processability [1,2]. Therefore, it can be widely used for high-performance pipes and high-strength films [3-6]. Molecular dynamics (MD) simulation acts as a useful and powerful tool that can be used to investigate the molecular mechanism of chain microstructures evolution at the molecular level.

The crystallization of polymer is known as a two-step process, first, primary nucleation which can be characterized by the emergence of nanometer-sized embryos $[7,8]$, and second, crystal growth 
which is the subsequent growth process of the embryos. Although the crystal growth process has been extensively investigated by experiments and simulations [9-16], the first stage, primary nucleation, did not receive too much attention [17,18]. Anwar et al. conducted MD simulations of nucleation in a polyethylene (C500) melt, and discovered that the nucleation process can be described in three stages: chain segments alignment, chain straightening and densification [19]. Zerze et al. proposed an alternative method to define ordered domains and growing nuclei based on an eicosane system [20]. Rutledge et al. calculated the interfacial free energy and nucleation rate based on a cylinder model in the homogenous nucleation of $\mathrm{C} 150$ and $\mathrm{C} 1000$ chains [21,22]. Su et al. observed that the trans-rich sequences aggregate in the formation process of the embryo [23]. Sanmartín et al. reported that the nucleation processes of branched ultralong $n$-alkanes start later than that of linear chain system [24]. In our previous work, the branch effects on the crystallization process of PE chain were explored and trans-rich phenomenon in the initial stage of nucleation was observed [25]. The crystallization mechanism of a series of linear PE chains with different chain length under a wide range of temperature was also explored [26]. Most recently, the molecular-level understanding of the short-chain branching (SCB) effect on the nucleation process of BPE has been revealed using bimodal blends of a short PE chain (C1000) and a long PE chain (C10000) with SCB distributed on either the short PE chain or the long PE chain [27]. BPE models with SCB incorporated in the long PE chain nucleate much later than those with SCB incorporated in the short PE chain. Moreover, the nucleation process can be further delayed when the branch length is increased. However, the BPE models built in our previous work are relatively simple, and seems to deviate from the normal industrial BPE a lot. The weight ratio of the long PE chain to the short PE chain in the BPE models is about 10:1, while the normal industrial BPE is about 1:1. Also, there is no current experimental work or simulation research about the methylene sequence length (MSL, the number of methylene units between any two adjacent branches) effects on the initial stage of the nucleation process of BPE, such as the formation of precursors, and the transformation of precursors to stable nuclei. So further study of the effects of SCB and MSL on the initial stage of nucleation for more complex BPE models, which are much closer to the normal industrial BPE, is very necessary.

Improved understanding of the branch effect on PE crystallization has been achieved due to a large number of investigations through experiments and simulations. Mandelkern et al. discovered that melting temperatures of ethylene copolymers decreased with the increasing branch content, but were independent of branch length [28,29]. Liu et al. explored branch effects on ethylene-1-hexene copolymer crystallization and found that the lamellae thickness decreased when branch content increased, accompanied by the transition of the final morphologies [30]. Wagener et al. [31-38] prepared branched polyethylene with SCB evenly incorporated in the linear backbone by using the acyclic diene metathesis (ADMET) method. They observed that melting temperatures decreased as branch content increased, and branch length began to show great impact on the melting temperatures only at a high branch content (e.g., $>50 \mathrm{SCB} / 1000$ backbone carbons). As it is a challenge for the current experimental techniques to observe much smaller spatial scales and time scales of physical changes, computer simulation provides another valuable vehicle to disclose the molecular mechanism of SCB on PE crystallization. Zhang et al. [39-42] performed a series of MD simulations to study the branch effects on the crystallization process of low-density polyethylene, and found that branch content and branch length could greatly influence the lamellar structure formation process. Ramos et al. [43] reported that the lamellar thickening processes of the branched polyethylene samples were impeded when compared with that of the linear polyethylene system. Choi et al. [44-46] investigated the branch effects on the structure of linear low-density polyethylene, and identified a critical branch content ( $38.5 \mathrm{SCB} / 1000$ backbone carbons) where the branch length began to influence the order parameter. Rutledge et al. [47] observed that the interfacial region's thicknesses of linear polyethylene systems were bigger than those found for branched systems. Although many research works focused on the PE crystallization, the investigation of the branch effects on BPE crystallization is still very lacking. Krishnaswamy et al. [48] examined the SCBD effect on crystallization behavior of 
high-density polyethylene (HDPE) using blends of low and high molecular weight PE chains with branches distributed on either the low or the high molecular weight PE chain. In our previous study, the placement of branches on the long PE chain resulted in much lower crystallinity as compared with that of branches on the short PE chain when branch content exceeded 5 SCB/1000 backbone carbons [27]. This critical branch content was not influenced by branch length. BPE models with branches incorporated in the long chain tended to form more tie chains relative to those with branches incorporated in the short chain. The tie chains concentration was independent of branch length. As mentioned above, these BPE models are relatively simple, deviating far from the normal industrial BPE. Moreover, the MSL effects on the crystallization process and also the tie chain formation process of BPE models were not considered as the MSL between the two different types of BPE models built in the previous work is quite different. What about if the MSL between the two kinds of BPE models is very comparable? So this is another key issue to be addressed in the present work.

The purpose of this work is to study the molecular mechanism of SCB, especially MSL, as well as the SCBD mechanism on the crystallization process of BPE. This study is an extension of our previous simulation for the simple BPE models [27]. The motivation for this study is three-fold. First, increase the number of short chain in the BPE models built in our previous study, so that these models can be much closer to the normal industrial BPE. Second, consider the MSL effect on the initial stage of nucleation of BPE. Third, investigate the MSL effects on the crystallization process and tie chain formation process of BPE. So MD simulations were carried out for two types of more complex BPE models which have the same branch content, branch length and comparable MSL, but different SCBD. The molecular mechanism of SCB and MSL on the initial stage of nucleation, also the crystal structures and especially the tie chains of BPE models were systematically studied.

\section{Models and Methods}

As shown in Figure 1, two kinds of precisely branched BPE models were built in accordance with industrial BPE pipe resins in this study. Each kind of BPE model contained 11 chains: one long chain with 10,000 $\mathrm{CH}_{2}$ in backbone and ten short chains with $1000 \mathrm{CH}_{2}$ in backbone for each short chain. One kind contained branches incorporated evenly in the long chain (Lb/10S), but the other kind contained branches incorporated evenly in the ten short chains (L/10Sb). It is worth noting that $\mathrm{Lb} / 10 \mathrm{~S}$ and L/10Sb systems have the same branch content, branch length but different SCBD: branches all incorporated in the long chain (Lb/10S) or in the short chains (L/10Sb). In our previous work, two kinds of simple BPE models which consist of only one long chain with 10,000 $\mathrm{CH}_{2}$ in backbone and one short chain with $1000 \mathrm{CH}_{2}$ in backbone were built [27]. These two types of simple BPE models also have the same branch content, branch length but different SCBD: branches incorporated in the long chain $(\mathrm{Lb} / 1 \mathrm{~S})$ or in the short chain $(\mathrm{L} / 1 \mathrm{Sb})$. For convenience, here we call the models built in our previous work as simple BPE models (Lb/1S and L/1Sb), and models built in the present work as complex BPE models (Lb/10S and L/10Sb). Unless otherwise stated, BPE models include the simple BPE models and the complex BPE models. It is very clear that the number of short chains in the complex BPE model was ten, which was greater than that in the simple BPE model. The complex BPE model which contained about $20,000 \mathrm{CH}_{2}$ in total was much larger than the simple BPE model as it contained only $11,000 \mathrm{CH}_{2}$ in total. Also, the molecular weight distribution of the complex BPE model was different from that of the simple BPE model. Table 1 summarizes the details of the complex BPE models used in this work. As the branch content of normal industrial BPE is very low, which ranged from 2 to 5 branches per 1000 carbons, such as the average branch content of Borstar BPE (PE100) is about 2.1 branches per 1000 carbons [6], so in this work, we choose to study the complex BPE models with branch content ranged from 0 to $8 \mathrm{SCB} / 1000$ backbone carbons. The naming method for these complex BPE models recognizes the composition of the models, also the branch type, and the branch content. For example, Lb/10S-C2-1 represents the blend of one branched long chain (Lb) with ethyl branches (C2) and ten linear short chains (10S), and the average branch content of this model is $1 \mathrm{SCB} / 1000$ backbone carbons ("1"). However, L/10Sb-C2-1 represents the blend of one linear long chain (L) and 
ten branched short chains (10Sb) with ethyl branches (C2), and the average branch content of this model is $1 \mathrm{SCB} / 1000$ backbone carbons (" 1 "). We also considered the branch length effect in this study. The butyl or hexyl branched complex BPE models (not shown here) were designed similarly to the ethyl branched complex BPE models, and the differences are the branch length. Each methylene or methyl unit, $\mathrm{CH}_{2}$ or $\mathrm{CH}_{3}$ unit, in all the models built in this work was treated as a united atom in order to simplify the calculation [49].

MD simulations were carried out using GROMACS 4.5.5 [50], with the Dreiding II force field [51]. The Dreiding II force field is a generic force field that is very widely used for PE due to the hexagonal crystal structure of PE chains that can be obtained in simulations [23,27,52-55]. Due to the lower torsional barrier heights from the gauche conformation to the trans conformation, polymer crystallization can be faster, which will lead to a significant saving in CPU time. Choi et al. discussed the effects of this force field on the folding process of PE chains and found that the choice of force fields was very important for PEs with high crystallinity [56]. Reduced units for time, distance, temperature and energy were used in this work: (1) The normalized time $\left(t^{*}\right)$ was given in $\tau$ units, and we set $t^{*}=1 \tau$ which stands for the real-time of 1 ps. (2) The normalized distance $\left(l^{*}\right)$ was given in $\sigma$ units, and we set $l^{*}=1 \sigma$ which stands for the real distance of $1 \mathrm{~nm}$. (3) The normalized temperature $\left(T^{*}\right)$ was calculated as $T^{*}=\mathrm{k}_{\mathrm{B}} \mathrm{T} / \varepsilon$, where $T$ is the real temperature, $\mathrm{k}_{\mathrm{B}}$ is the Boltzmann constant $\left(\mathrm{k}_{\mathrm{B}}=8.3145 \times 10^{-3} \mathrm{~kJ} \mathrm{~mol}^{-1} \mathrm{~K}^{-1}\right)$, and $\varepsilon$ is the van der Waals interaction parameter $(\varepsilon=0.8301 \mathrm{~kJ}$ $\mathrm{mol}^{-1}$ ) in a 12-6 Lennard-Jones potential of Dreiding II force field [51]. We set the normalized temperature $T^{*}=8.0$, which stands for the real temperature $T=800 \mathrm{~K}$. (4) The normalized energy $\left(E^{*}\right)$ was given in $\xi$ units, and we set $E^{*}=1 \xi$ which stands for the real energy of $1 \mathrm{~kJ} / \mathrm{mol}$. The velocity Verlet algorithm was chosen for the integration of the equations of motion, where the time step was set at $2 \times 10^{-3} \tau$.

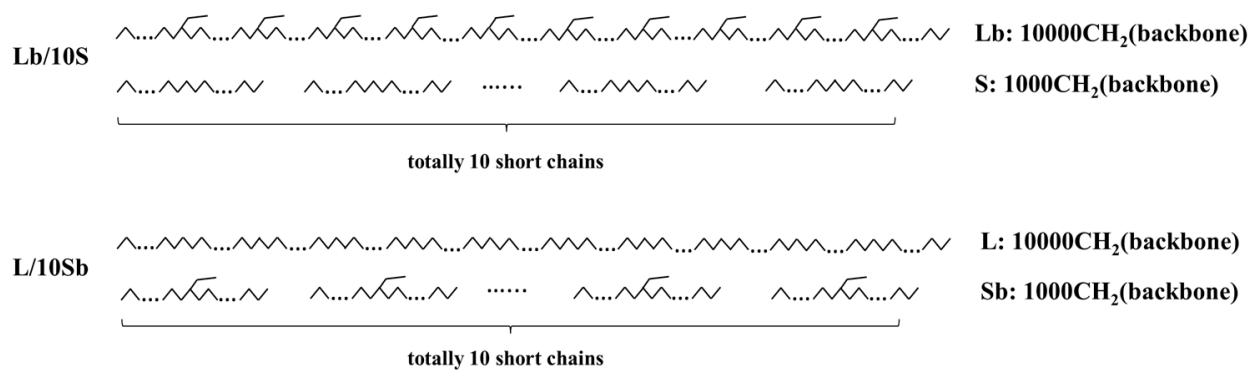

Figure 1. Chain architectures of two kinds of bimodal polyethylene (BPE) models (Lb/10S and L/10Sb) built in this work. Both these two kinds of BPE models consisted of one long chain (backbone: 10,000 $\mathrm{CH}_{2}$ ) and ten short chains (backbone of each short chain: $1000 \mathrm{CH}_{2}$ ), but with different short-chain branching distribution (SCBD). One type contained branches which incorporated equally in the long chain $(\mathrm{Lb} / 10 \mathrm{~S})$ while the other type contained branches incorporated equally in the ten short chains $(\mathrm{L} / 10 \mathrm{Sb})$.

A canonical NVT ensemble was used for a vacuum state research, and the Nose-Hoover thermostat with a time constant of $0.5 \tau$ was used for the control of the temperature. In the simulation, the polymer was placed in the center of a cubic box, and the normalized distance from the end of the polymer chain to the closest edge of the box was set at about $l_{\mathrm{e}}^{*}=25 \sigma$ (the corresponding real distance is about $25 \mathrm{~nm}$, and the box size effect was discussed in the Supplementary Material). So the box size was fixed as 'very large' to contain the polymer so that enough empty space is reserved to maintain a vacuum condition where there was no boundary condition for all the polymer chains $[26,42,45,52,53]$. The density of the cubic box was kept constant throughout the crystallization process. However, the density change of the BPE models during the crystallization could be reflected through the variation of order parameters of the polymer chains which will be discussed in the following section. The calculations of all reported static properties of the polymer chains (e.g., order parameters) center on the coordinate of every $\mathrm{CH}_{2}$ unit and these surrounding voids are ignored. 
For the sake of achieving an equilibrium amorphous state at the first opportunity, the temperature adopted in this study was higher than that observed in the real experiment, and the temperature here was modified to the normalized temperature $\mathrm{T}^{*}$ (see Supplementary Material) [26,52]. The complex BPE models with an all-trans conformation were first minimized to remove high-energy overlaps, and then were annealed at $T^{*}=8.0$ for $t^{*}=3.0 \times 10^{4} \tau$ to obtain equilibrium amorphous coils. Here $T^{*}=8.0$ was corresponding to the real experimental temperature which was higher than the melting temperature of BPE, a detailed explanation can be found in the supplementary material. Then the amorphous structure was quenched from $T^{*}=8.0-3.0$ with a cooling rate of $\Gamma^{*}=2.5 \times 10^{-4} \tau^{-1}$, and at last the simulations were performed at $T^{*}=3.0$ for another $t^{*}=4 \times 10^{3} \tau$.

In order to quantify the crystallinity of the polymer chains, we followed a site order parameter (SOP) method proposed by Yang et al. [52]. The SOP of site $k$ is calculated as follows, where $i$ and $j$ are any two-unit vectors in the domain with radius $R=0.55 \sigma$ surrounding the site:

$$
\mathrm{SOP}_{\mathrm{k}}=\frac{\left\langle 3 \cos ^{2}(\varphi)-1\right\rangle}{2}=\frac{3}{2}\left\langle\left(\overrightarrow{\mathrm{e}}_{\mathrm{i}} \cdot \overrightarrow{\mathrm{e}}_{\mathrm{j}}\right)^{2}\right\rangle_{\mathrm{R}}-\frac{1}{2}
$$

Table 1. Characteristics of the branched complex BPE models with different branch content and SCBD ${ }^{\mathrm{a}}$.

\begin{tabular}{ccccc}
\hline $\begin{array}{c}\text { Complex BPE } \\
\text { Model }\end{array}$ & Branch & $\begin{array}{c}\text { Branch Content } \\
\text { (SCB/1000 Backbone } \\
\text { Carbons) }\end{array}$ & $\begin{array}{c}\text { Methylene } \\
\text { Sequence Length } \\
\text { (CH } \mathbf{~})\end{array}$ & $\begin{array}{c}\text { Total Number of } \\
\mathbf{C H}_{\mathbf{2}}\end{array}$ \\
\hline HDPE & None & 0 & - & 20,000 \\
Lb/10S-C2-1 & Ethyl & 1 & 476 & 20,036 \\
L/10Sb-C2-1 & Ethyl & 1 & 334 & 20,060 \\
Lb/10S-C2-2 & Ethyl & 2 & 244 & 20,084 \\
L/10Sb-C2-2 & Ethyl & 2 & 200 & 20,080 \\
Lb/10S-C2-3 & Ethyl & 3 & 164 & 20,124 \\
L/10Sb-C2-3 & Ethyl & 3 & 142 & 20,060 \\
Lb/10S-C2-4 & Ethyl & 4 & 124 & 20,204 \\
L/10Sb-C2-4 & Ethyl & 4 & 112 & 20,240 \\
Lb/10S-C2-5 & Ethyl & 5 & 100 & 20,300 \\
L/10Sb-C2-5 & Ethyl & 5 & 92 & 20,320 \\
Lb/10S-C2-6 & Ethyl & 6 & 82 & 20,162 \\
L/10Sb-C2-6 & Ethyl & 6 & 76 & 20,120 \\
Lb/10S-C2-7 & Ethyl & 7 & 70 & 20,150 \\
L/10Sb-C2-7 & Ethyl & 7 & 66 & 20,180 \\
Lb/10S-C2-8 & Ethyl & 8 & 62 & 20,302 \\
L/10Sb-C2-8 & Ethyl & 8 & 58 & 20,180 \\
\hline
\end{tabular}

${ }^{a}$ The design of branched complex BPE models with butyl or hexyl branches (not shown here) are the same as the complex BPE models with ethyl branches, and the differences are the branch length.

For a system which contains $\mathrm{N}$ sites, the SOP of this system is defined as the average of $\mathrm{SOP}_{\mathrm{k}}$ of all the sites in the system:

$$
\mathrm{SOP}=\frac{1}{\mathrm{~N}} \sum_{\mathrm{k}=1}^{\mathrm{N}} \mathrm{SOP}_{\mathrm{k}}
$$

The Crystallinity $\left(X_{c}\right)$ of this polymer system can then be calculated by the proportion of sites with $\mathrm{SOP}_{\mathrm{k}}$ higher than 0.7 [52].

The orientation vectors in the ordered domains where $\mathrm{SOP}_{\mathrm{k}}$ are higher than 0.7 are deemed to locate in the same nucleus only when the distance between any two of the orientation vectors is less than about $0.68 \sigma$, and also the average cosine of angle between these vectors is higher than 0.82 [20]. So, the entire ordered region is grouped into different clusters, and clusters that contain more than 30 monomers are considered as nuclei or crystal domains. 
In addition to the site order parameter, the dihedral distribution of the polymer system was also calculated. The proportion of a dihedral angle $\mathrm{m}$ along the backbone of the polymer chains is defined as follows:

$$
\mathrm{P}_{\mathrm{m}}=\frac{\mathrm{N}_{\mathrm{m}}}{\sum \mathrm{N}_{\mathrm{m}}},
$$

where $N_{\mathrm{m}}$ is the number of atoms with the dihedral angle $\mathrm{m}\left(\mathrm{m}=0^{\circ}-360^{\circ}\right)$. The trans state corresponds to the torsion angle between $180^{\circ} \pm 15^{\circ}$.

To determine the entanglement density of this polymer system, a parameter named as interchain contact fraction (ICF) was introduced by Yang et al. [52]. It can be calculated using the equation below:

$$
\mathrm{ICF}=\frac{\sum \mathrm{N}_{\text {inter }}\left(\mathrm{r}_{\mathrm{n}}\right)}{\sum \mathrm{N}_{\text {total }}\left(\mathrm{r}_{\mathrm{n}}\right)},
$$

where $N_{\text {inter }}\left(r_{\mathrm{n}}\right)$ signifies the number of interchain units around a certain unit at distance $r_{\mathrm{n}}$, and $N_{\text {total }}\left(r_{\mathrm{n}}\right)$ signifies the number of total units $\left(N_{\text {total }}\left(r_{\mathrm{n}}\right)=N_{\text {inter }}\left(r_{\mathrm{n}}\right)+N_{\text {intra }}\left(r_{\mathrm{n}}\right)\right)$ around the same unit. The distance $r_{n}$ ranges from 0.48 to $0.52 \sigma$.

\section{Results and Discussion}

\subsection{Induction Time of Precursor Formation}

We first concentrated our attention on the precursor formation during the induction period of BPE models. The time evolutions of non-bonding potential energy (vdW energy) and structure parameters $\left(\mathrm{R}_{\mathrm{g}}, \mathrm{X}_{\mathrm{c}}\right.$ and trans-state population) for L/10Sb-C4-1 model and Lb/10S-C4-1 model are shown in Figure 2, respectively. There are three stages according to the evolutions of these parameters for the two models: an induction period, a rapid growth stage and a final stable period. For instance, vdW energy decreased slightly at the first $t^{*}=7 \times 10^{3} \tau$, then it decreased remarkably until $t^{*}=2.0 \times 10^{4} \tau$, and after $2.0 \times 10^{4} \tau$, it remained almost unchanged. The similar phenomena were also observed for the corresponding $\mathrm{Rg}$, $\mathrm{X}_{\mathrm{c}}$ and trans-state population of the two models. During the induction period, $\mathrm{R}_{\mathrm{g}}$ decreased slightly, and trans-state population increased slowly, while $\mathrm{X}_{\mathrm{c}}$ kept at around 0 . A new trans-rich structure (also precursor) formed in this period due to the transformation of dihedral angle of bonds from random trans/gauche states to trans states [25]. However, the increase of crystallinity was found to lag behind this trans-rich phenomenon. There was a turning point from the induction period to the rapid growth stage, which was the endpoint of the induction period, as well as the induction time of precursor formation. Before this turning point, $\mathrm{X}_{\mathrm{c}}$ was stable at around 0 , and after this turning point, $X_{c}$ began to increase. Therefore, we define this turning point as the endpoint of the induction period where the crystallinity of the precursor reached about 0.005 [25].

The corresponding trans state $\left(180^{\circ} \pm 15^{\circ}\right)$ populations along the backbone of all the two types of precisely branched BPE models at the induction time are about 0.33 , as shown in Figure 3 . The SCBD dependence of induction time $\left(t_{\mathrm{p}}{ }^{*}\right)$ and the corresponding trans-state population for the two kinds of complex BPE models with different branch length [Figure 3a-c] and the two types of simple BPE models with different branch length [Figure 3d-f] are clearly shown in Figure 3, respectively. For the case of ethyl branches incorporated in the ten short chains, we use L/10Sb-C2-ind-time and $\mathrm{L} / 10 \mathrm{Sb}-\mathrm{C} 2$-trans to represent the induction time and the corresponding trans-state population of this system, but for the case of ethyl branches incorporated in the long chain, we use Lb/10S-C2-ind-time and Lb/10S-C2-trans instead. The naming conventions for those butyl or hexyl branched BPE models are similar to the ethyl branched systems. 

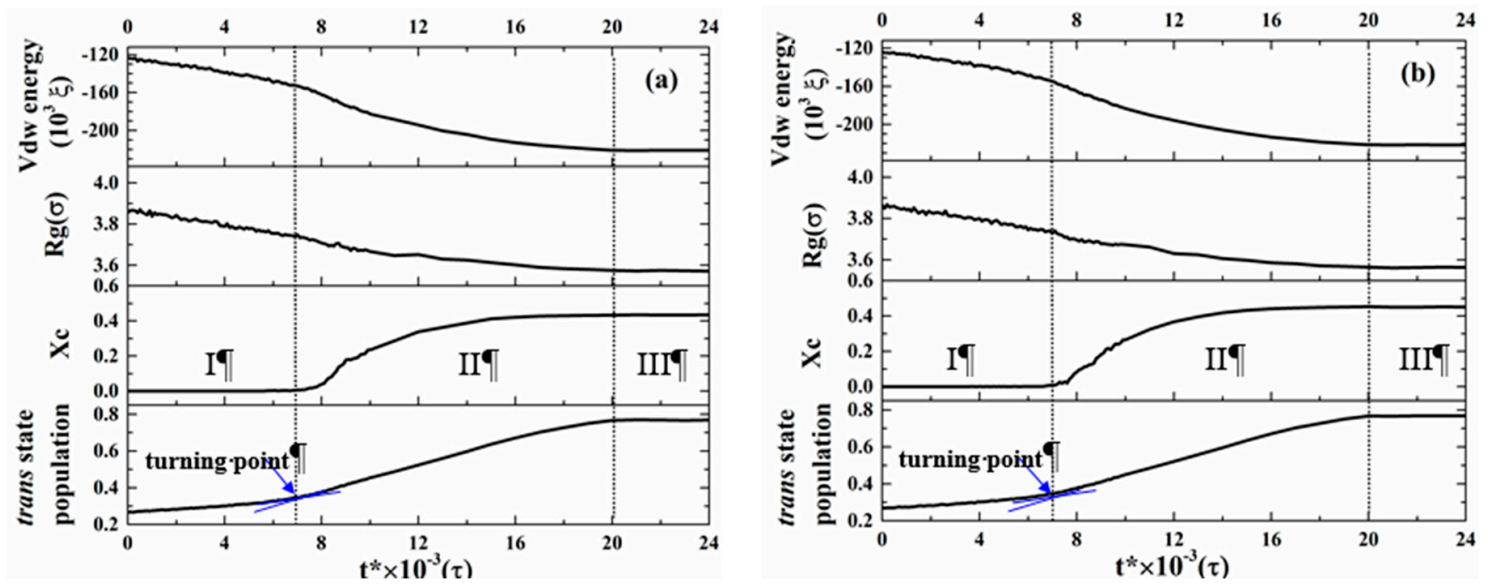

Figure 2. Evolution curves of van der Waals energy, $R_{g}, X_{c}$ and trans-state population for (a) L/10Sb-C4-1 model and (b) Lb/10S-C4-1 model. Note that these parameters of the model are the averages of the long chains and short chains in the model. The crystallization process of complex BPE is divided into three stages: I: an induction period, II: a rapid growth stage, III: a final stable period.

Comparing the ethyl branched Lb/10S system and Lb/1S system, the induction time of the $\mathrm{Lb} / 10 \mathrm{~S}-\mathrm{C} 2$ system was longer than that of $\mathrm{Lb} / 1 \mathrm{~S}-\mathrm{C} 2$ system. When the branch length changed to butyl and hexyl, the results were also very similar. This may be explained by the lower MSL of Lb/10S system when compared with that of Lb/1S system, as shown in Table $\mathrm{S} 1$ in the supplementary material. The details of the MSL of the simple BPE models and the complex BPE models are shown in Table S1 (in the supplementary material). Hence, it seems that the induction time of precursor formation is determined by the MSL of the system. The induction time of the precursor formation prolonged with the decrease of the MSL of the system.

The induction time increased with the increasing branch content for all the complex BPE models (L/10Sb system and Lb/10S system). This behavior is consistent with that of a single branched PE chain [25]. For the two kinds of complex BPE models, it is clearly observed that the induction time of $\mathrm{Lb} / 10 \mathrm{~S}$ systems is longer than that of $\mathrm{L} / 10 \mathrm{Sb}$ systems. More interesting, the difference of induction time of the precursor formation between these two kinds of complex BPE models increased when branch length increased from the ethyl branch to hexyl branch. The similar phenomena were observed for the simple BPE models, as shown in Figure 3d-f. Therefore, for all the two kinds of BPE models, $\mathrm{SCB}$ incorporated in the long chain leads to a delay of induction period relative to the case of SCB incorporated in the short chain, and this delay effect increased with the increasing branch length.

Figure 4 depicts the branch length dependence of induction time for the two kinds of complex BPE models. As observed, the induction time increased as branch length increased for both $\mathrm{L} / 10 \mathrm{Sb}$ systems and $\mathrm{Lb} / 10 \mathrm{~S}$ systems, but $\mathrm{Lb} / 10 \mathrm{~S}$ systems show a bigger difference. For the simple BPE models, the phenomena were also very similar, as shown in Figure S2 in the supplementary material. Hence, the induction periods for all the BPE models were delayed as branch length increased. Additionally, this delay effect will become worse for BPE models with SCB incorporated in the long chain as compared to that with SCB incorporated in the short chain. 

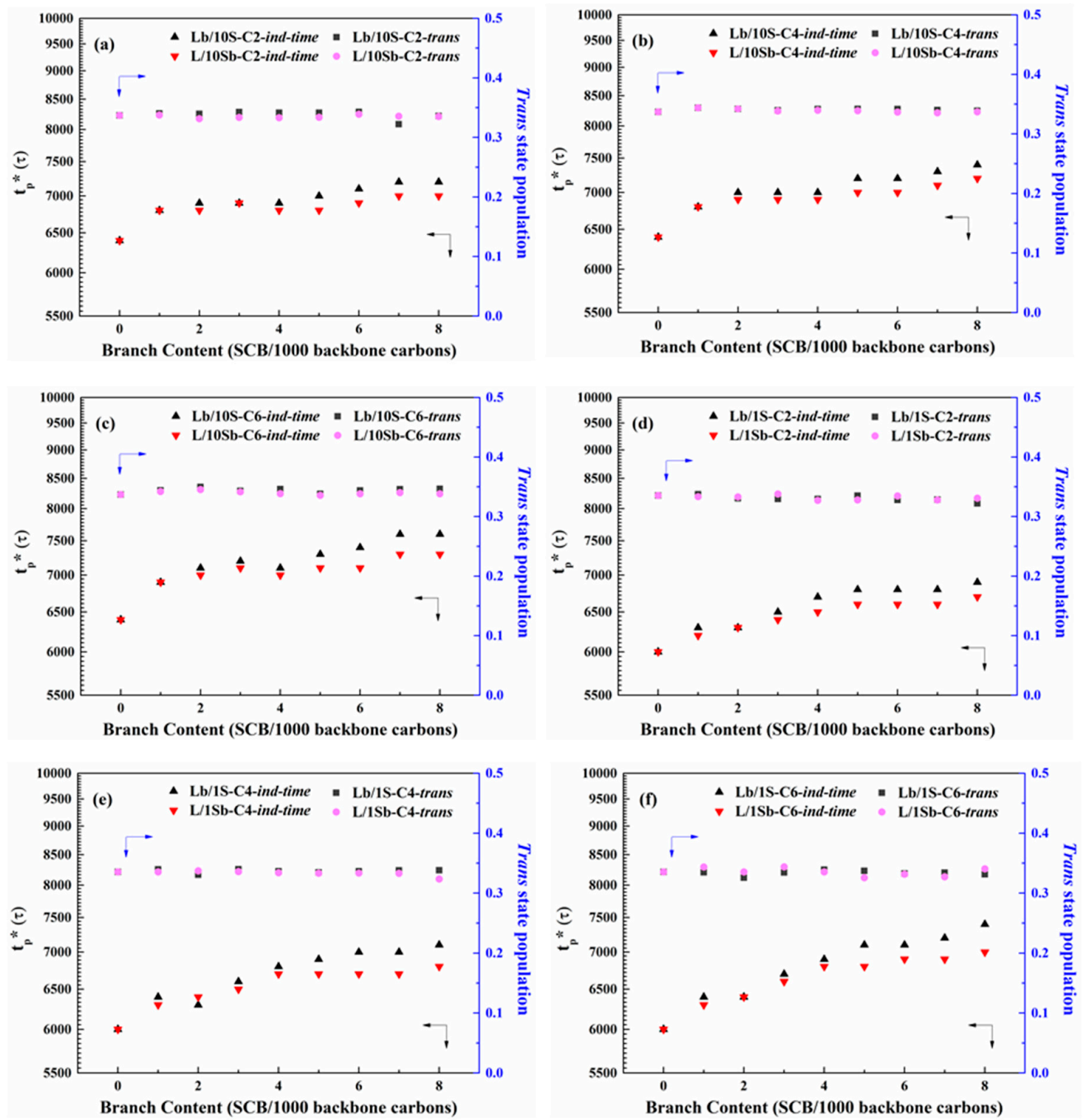

Figure 3. SCBD dependence of induction time $\left(t_{\mathrm{p}}\right.$ *) and trans-state population for the two kinds of complex BPE models with (a) ethyl branches, (b) butyl branches and (c) hexyl branches and the two kinds of simple BPE models with (d) ethyl branches, (e) butyl branches and (f) hexyl branches.
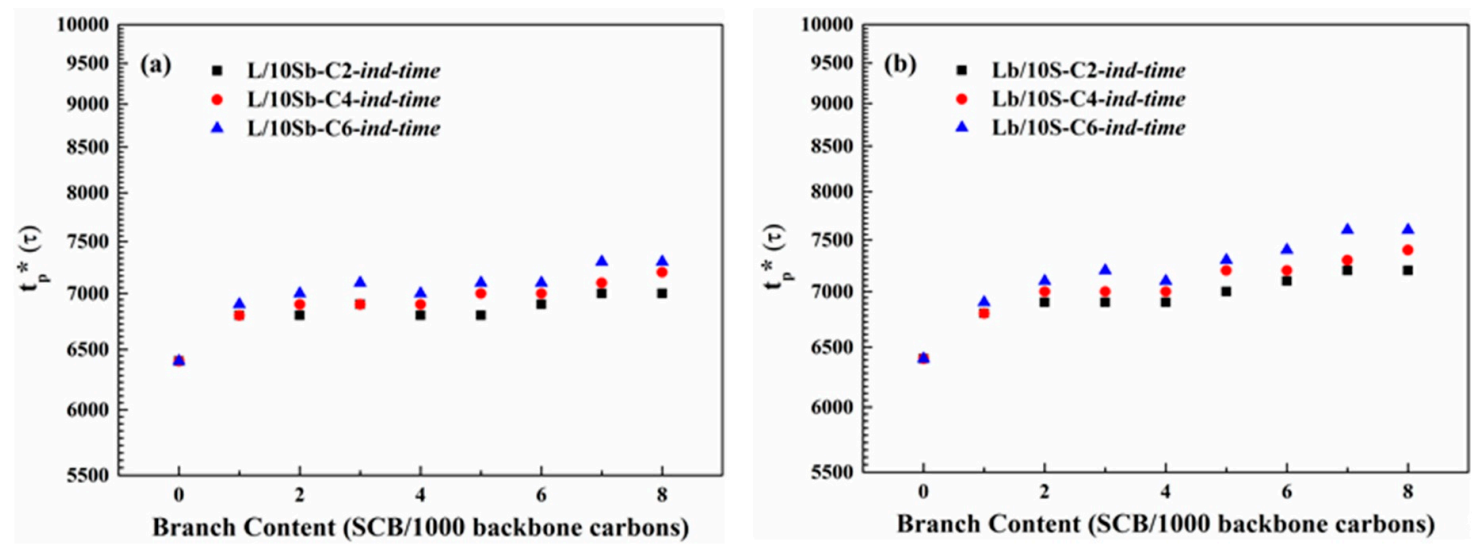

Figure 4. Branch length dependence of induction time $\left(t_{\mathrm{p}}{ }^{*}\right)$ for (a) L/10Sb systems and (b) Lb/10S systems. 


\subsection{The Transformation of Precursors to Stable Nuclei}

Parts of the precursors forming during the induction period will be transformed into stable nuclei. The first stable nucleus means the first nucleus transformed by the precursors, meanwhile, this nucleus could exist for a relatively long period (often several hundred $\tau$ ) [27]. Note that if the formed first nucleus disappears very soon (less than $100 \tau$ ), it was not considered as the first stable nucleus. The formation time of the first stable nucleus was defined as the time when this nucleus emerged. We then traced the first stable nucleus formation process and attained the details of the nucleus structure. In order to analyze the nucleus structure, we introduced another parameter named long-chain proportion (LCP) [27]. LCP corresponds to the ratio of long-chain carbons to the total carbons in the first stable nucleus.

Figure 5 exemplifies the SCBD effect on the first stable nucleus formation time $\left(t_{\mathrm{n}}{ }^{*}\right)$ and the corresponding LCP for the BPE models with different branch lengths. Comparing the Lb/10S-C2 system with the Lb/1S-C2 system, the first stable nucleus formation time of the Lb/10S-C2 system was longer than that of the Lb/1S-C2 system. It was also observed that the differences of the first stable nucleus formation time between these two systems decreased with the increasing branch content. Similar phenomena were also observed for the butyl- or hexyl-branched Lb/10S systems and Lb/1S systems. This may also result from the lower MSL of the Lb/10S system when compared with that of the Lb/1S system, and much smaller MSL differences when the branch content increased, as shown in Table S1 in the supplementary material. Therefore, the first stable nucleus formation time was influenced by the MSL of the system. The first stable nucleus formation time increased with the decrease of MSL of the system.

It is observed that for the two different kinds of complex BPE models, the first stable nucleus formation time both increase with the increasing branch content. More interesting, the first stable nucleus formation time of $\mathrm{L} / 10 \mathrm{Sb}$ systems were much shorter than that of $\mathrm{Lb} / 10 \mathrm{~S}$ systems. For the simple BPE models, the first stable nucleus formation time of $\mathrm{L} / 1 \mathrm{Sb}$ systems was also much shorter than that of Lb/1S systems [27]. Hence, SCB incorporated in the long chain will result in a delay to the nucleation process when compared with that of SCB incorporated in the short chain.

As depicted in Figure 5a, the LCP of Lb/10S-C2 system in the nucleus was much lower than that of the Lb/1S-C2 system. Also, the LCP of the L/10Sb-C2 system was lower than that of the L/1Sb-C2 system. When the branch length increased to butyl or hexyl, the phenomena were also very similar, as shown in Figure 5b,c. This may be attributed to the different MSL between the simple BPE model and the complex BPE model. As the MSLs of Lb/10S systems are much shorter than those of Lb/1S systems (see Table S1 in supplementary material), it was more difficult for the long-chain components of $\mathrm{Lb} / 10 \mathrm{~S}$ systems to nucleate in comparison with those of $\mathrm{Lb} / 1 \mathrm{~S}$ systems, thereby leading to much lower LCPs of Lb/10S systems. Due to the longer MSLs of L/10Sb systems in comparison with those of $\mathrm{L} / 1 \mathrm{Sb}$ systems (see Table $\mathrm{S} 1$ in the supplementary material), short-chain components in L/10Sb systems can participate in the nucleation process, while those in $\mathrm{L} / 1 \mathrm{Sb}$ systems cannot. Therefore, the LCPs of $\mathrm{L} / 10 \mathrm{Sb}$ systems will be much lower than those of $\mathrm{L} / 1 \mathrm{Sb}$ systems. Moreover, it is intriguing to find that the MSLs of $\mathrm{L} / 10 \mathrm{Sb}$ systems are all longer than about $60 \mathrm{CH}_{2}$, and the short chains in $\mathrm{L} / 10 \mathrm{Sb}$ systems will participate in the nucleation process. However, the MSLs of L/1Sb systems are almost shorter than $60 \mathrm{CH}_{2}$, and the long chains in L/1Sb systems will be predominant in the nucleation process. Hence, it seems that only when the MSLs of the BPE models are longer than $60 \mathrm{CH}_{2}$, then the branched chains can nucleate. Ungar et al. reported that the shortest folded chain length was 150 carbons when polymer crystallized from solution [57]. Zerze et al. [20] and Rutledge et al. [22] found such a critical fold length was 20-30 carbons when polyethylene crystallized from the melt. Flory discovered that at each crystallization temperature there was an MSL for a polymer chain to crystallize [58]. The critical MSL $\left(60 \mathrm{CH}_{2}\right)$ for a branched chain to nucleate obtained in this work was longer than the critical fold length (20-30 carbons) reported about polymer crystallization from the melt. But it was shorter than the critical fold length (150 carbons) reported about the polymer crystallization from solution, which is 
due to the interaction between polymers and solvent molecules in solution. So in general, the critical MSL $\left(60 \mathrm{CH}_{2}\right)$ for a branched chain to nucleate derived from this work is reasonable.

Obviously, the LCPs of L/10Sb systems in the nucleus increased slightly as branch content increased. However, the LCPs of $\mathrm{Lb} / 10 \mathrm{~S}$ systems decreased with the increasing branch content, and all were lower than $60 \%$. This may be due to the decrease of MSLs of the long chains in Lb/10S systems and the short chains in L/10Sb systems, respectively. More interesting, the LCPs of L/10Sb systems are higher than those of $\mathrm{Lb} / 10 \mathrm{~S}$ systems, which suggest that when the MSLs of them are comparable (see the supplementary material Table S1), both short chain and long chain of them can take part in the nucleation process, and SCB incorporated in the long chain will hinder the long chain from nucleating relative to the case of SCB incorporated in the short chains. Therefore, the nucleation processes of BPE models were determined by the MSLs of them. The critical MSL for a branched chain to nucleate is about $60 \mathrm{CH}_{2}$. The percentage of the long-chain carbons to nucleate increased as the MSL of the model increased. It needs to mention that the LCPs of L/1Sb systems and Lb/1S systems are all higher than $90 \%$ although the MSLs of them decreased with the increasing branch content. It may be explained by the strong molecular weight effect of the long chain to the short chain on the chain conformational relaxation time. As a result, long chain predominates in the nucleation for the simple BPE models. But for the complex BPE models, it seems that MSL has a greater influence than molecular weight, thereby short chains and long chains of the models will nucleate together to form the first stable nucleus.

To better understand the formation process of the first stable nucleus, we analyzed the microstructures of the first stable nucleus formed in the ethyl branched complex BPE models and simple BPE models, as shown in Figure 6. The long-chain carbons in the first stable nucleus are colored in blue, and the short-chain carbons are colored in red. It is observed that long chains and short chains all participate in the formation processes of the first stable nucleus for the complex BPE models (Lb/10S-C2 system and L/10Sb-C2 system), while for the simple BPE models (Lb/1S-C2 system and $\mathrm{L} / 1 \mathrm{Sb}-\mathrm{C} 2$ system), only long chains take part in the formation processes of the first stable nucleus. So the LCP of Lb/10S-C2 system was much lower than that of Lb/1S-C2 system. Similar behavior was also found for the $\mathrm{L} / 10 \mathrm{Sb}-\mathrm{C} 2$ system and $\mathrm{L} / 1 \mathrm{Sb}-\mathrm{C} 2$ system. The different nucleus structure between the complex BPE model and the simple BPE model was mainly explained by the different MSL between these models. As the MSL of the Lb/10S-C2 system is shorter than that of the Lb/1S-C2 system, the short chains in the Lb/10S-C2 system can get the chance to take part in the nucleation. Also, the MSL of the L/10Sb-C2 system is much longer than that of the L/1Sb-C2 system, so the short chains in the $\mathrm{L} / 10 \mathrm{Sb}-\mathrm{C} 2$ system can obtain the opportunity to participate in the nucleation. We also observed that when the MSL of the polymer chain is longer than $60 \mathrm{CH}_{2}$, increasing the proportion of the short chain in the model can increase the probability of participating in the nucleation of the short chain. Moreover, the percentage of long-chain carbons in the first stable nucleus of the L/10Sb-C2 system was higher than that of short chains, and increased a little with increasing branch content. But for the $\mathrm{Lb} / 10 \mathrm{~S}-\mathrm{C} 2$ system, the percentage of long-chain carbons in the first stable nucleus was much lower than that of short chains at high branch content $(>4 \mathrm{SCB} / 1000 \mathrm{C})$, and apparently decreased with the increasing branch content. The LCP of L/10Sb-C2 system was higher than that of Lb/10S-C2 system. These observations are in agreement with the LCPs of ethyl branched complex BPE models and ethyl branched simple BPE models, as shown in Figure 5. The similar phenomena are also observed for the butyl or hexyl branched systems. 

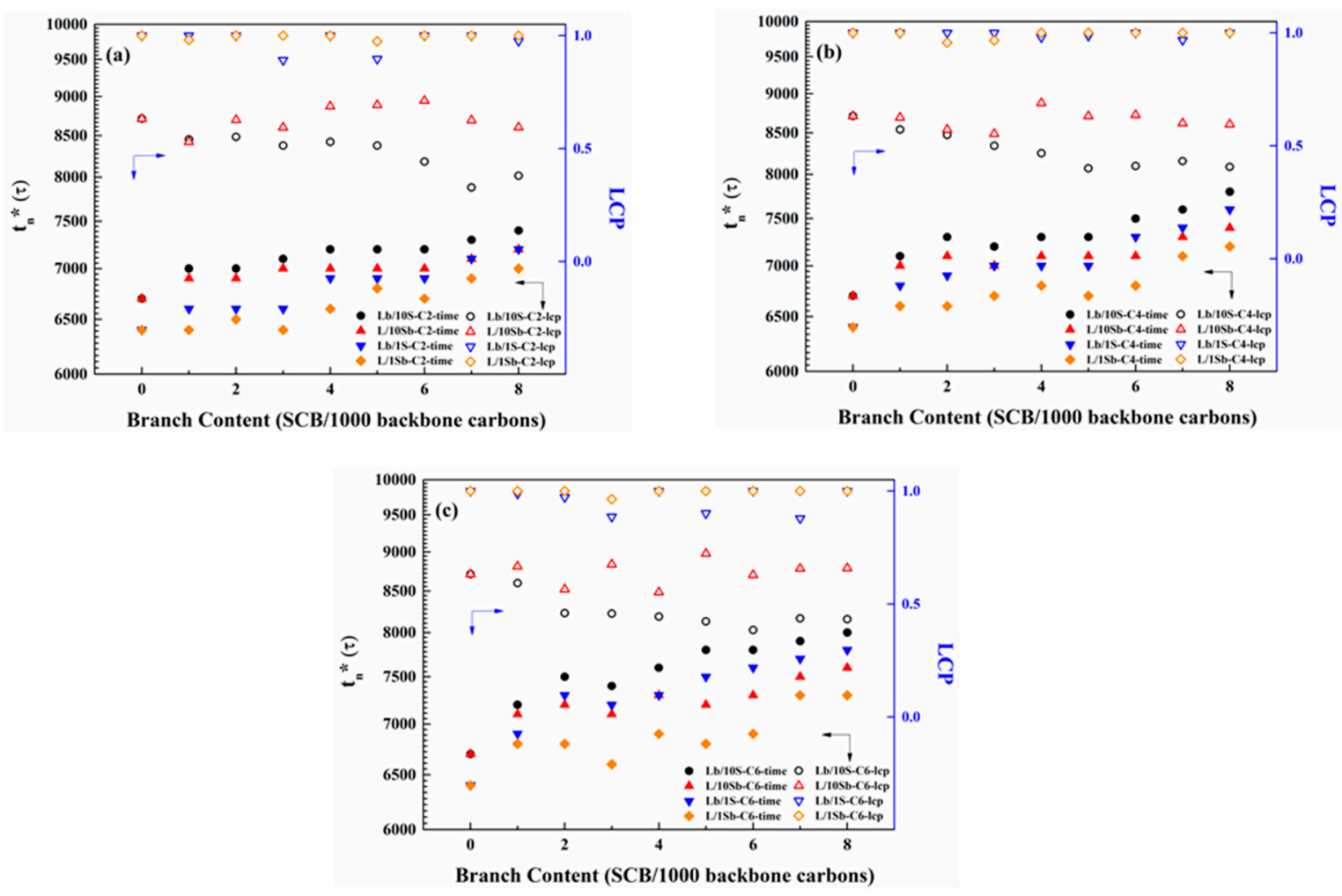

Figure 5. SCBD effect on the first stable nucleus formation time $\left(t_{\mathrm{n}}{ }^{*}\right)$ and long-chain proportion (LCP) for precisely branched complex BPE models and simple BPE models with (a) ethyl branches, (b) butyl branches and (c) hexyl branches. LCP: the ratio of long-chain carbons to the total carbons in the first stable nucleus [27]. Reprinted the data for the simple BPE models with permission from Ref. [27]. Copyright 2018 Elsevier Ltd.

The branch length dependence of the first stable nucleus formation time and LCP for the two kinds of complex BPE models are illustrated in Figure 7. The first stable nucleus formation time increased with the increasing branch length for both L/10Sb systems and Lb/10S systems, and the increase of $\mathrm{Lb} / 10 \mathrm{~S}$ systems was much more significant. This observation is also found in the simple BPE models [27]. Therefore, the nucleation processes for the two kinds of BPE models are delayed when the branch length increases. Additionally, the delay effect of branch length on the nucleation will become much worse when branches were incorporated in the long chain as compared to the case of branches incorporated in the short chain. A similar phenomenon was also observed for the ultralong $\mathrm{n}$-alkanes systems that the nucleation is delayed when the branch length increases [24]. The LCPs of $\mathrm{L} / 10 \mathrm{Sb}$ systems with a different branch length are in a range of $50 \%-70 \%$, which are insensitive to branch length, as depicted in Figure 7a. For Lb/10S systems, the LCPs are in a range of $35 \%-60 \%$, which are also independent of branch length, as depicted in Figure $7 \mathrm{~b}$. Hence, the LCPs of L/10Sb systems and $\mathrm{Lb} / 10 \mathrm{~S}$ systems are not influenced by branch length. For the two kinds of simple BPE models, the LCPs are also independent of branch length [27]. 


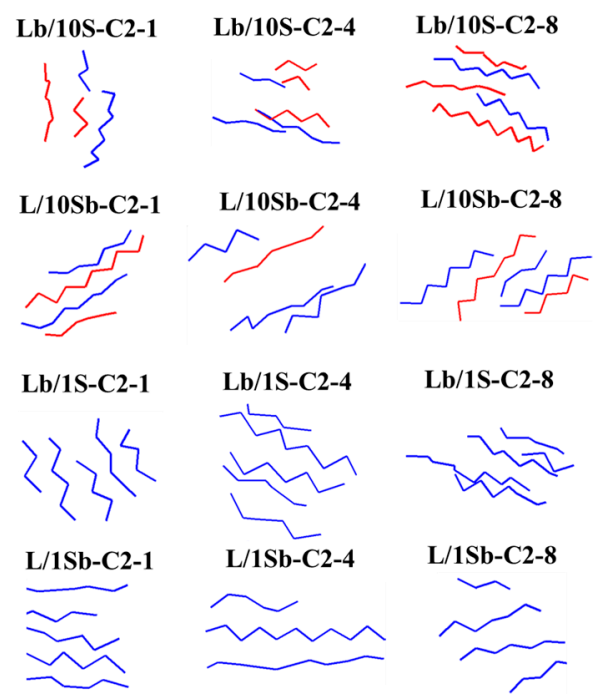

Figure 6. Microstructures of the first stable nucleus formed in the branched complex BPE models and simple BPE models with ethyl branches. Blue monomers represent the long-chain carbons in the first stable nucleus and red monomers represent the short-chain carbons in the first stable nucleus.
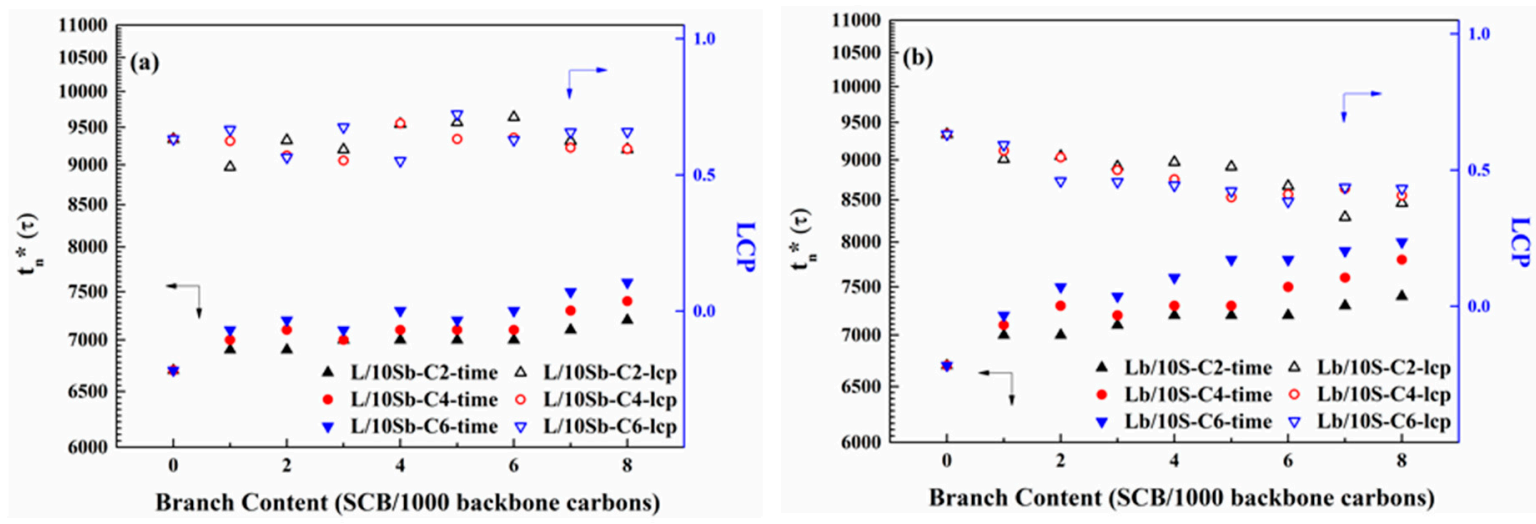

Figure 7. Branch length dependence of the first stable nucleus formation time $\left(t_{n}{ }^{*}\right)$ and LCP for (a) L/10Sb systems and (b) Lb/10S systems.

\subsection{Crystal Structures}

In order to deduce how SCB affects the chain crystal structures of the BPE models, we have computed the order parameter and crystallinity of the systems. Crystallization curves of different branch content for the two kinds of complex BPE models with different branch length, including ethyl, butyl and hexyl branches are shown in Figure S3 in the supplementary material. For the two kinds of ethyl branched complex BPE models, the values of $X_{c}$ all decreased with the increasing branch content. But the values of $X_{c}$ of the Lb/10S-C2 systems decreased more obviously with the increasing branch content than that of L/10Sb-C2 systems, as shown in Figure S3a,b (in supplementary material). When branch length changed to butyl or hexyl, the phenomena were also very similar (see Figure S3c- $\mathrm{f}$ in supplementary material) These observations are consistent with that of simple BPE models [27].

Figure 8 shows the SCBD effect on the $\mathrm{XC}_{\mathrm{C}}$ and SOP of the complex BPE models and the simple BPE models with different branch lengths. Comparing the Lb/10S-C2 system and the Lb/1S-C2 system, the $\mathrm{Xc}$ and SOP of the Lb/10S-C2 system were lower than that of the Lb/1S-C2 system, as shown in Figure 8a. When the branch length increased to butyl or hexyl, similar phenomena were also observed, as depicted in Figure $8 b$,c. This may be also due to the lower MSL of the Lb/10S system when compared with that of the Lb/1S system (see the Supplementary Material Table S1). Hence, the crystallinity of the polymer is influenced by the MSL of the system. The crystallinity of polymer reduced with the 
decrease of MSL of the system. It needs to be pointed out that the $\mathrm{Xc}_{\mathrm{c}}$ and SOP of the L/10Sb system are also lower than that of the L/1Sb system despite the MSL of the L/10Sb system being higher than that of the $\mathrm{L} / 1 \mathrm{Sb}$ system. This may be attributed to the fact that more nuclei will form in the $\mathrm{L} / 10 \mathrm{Sb}$ system when compared with the L/1Sb system, as shown in Figure S4 in the supplementary material (only shows the nuclei number of ethyl branched systems, the results of systems with butyl or hexyl branches are very similar), which may lead much lower crystallinity of the L/10Sb system.

As observed in Figure 8a, the $\mathrm{X}_{\mathrm{c}}$ and SOP of the ethyl branched complex BPE models (L/10Sb system and Lb/10S system) are not influenced by the two different SCBD up to a branch content of about $5 \mathrm{SCB} / 1000 \mathrm{C}$. Above $5 \mathrm{SCB} / 1000 \mathrm{C}, \mathrm{X}_{\mathrm{c}}$ and SOP of L/10Sb systems are much larger than that of $\mathrm{Lb} / 10 \mathrm{~S}$ systems. The first observation coincides with the findings of Krishnaswamy et al. where a similar density for two kinds of HDPE blends that have matched MWD and average branch content (3 SCB/1000C) were observed [48]. Hence, it seems that the SCBD effect becomes remarkable only at a high branch content ( $>5 \mathrm{SCB} / 1000 \mathrm{C}$ ). Moreover, this critical branch content does not change when the branch length increases to butyl or hexyl, as shown in Figure 8b,c. Also, these observations accord well with that of the simple BPE models [27]. More interestingly, the differences in $X_{c}$ (also SOP) between $\mathrm{Lb} / 10 \mathrm{~S}$ systems and L/10Sb systems were much lower than those between $\mathrm{Lb} / 1 \mathrm{~S}$ systems and $\mathrm{L} / 1 \mathrm{Sb}$ systems when branch content exceeds $5 \mathrm{SCB} / 1000 \mathrm{C}$. This may result from the lower MSL differences between the two types of complex BPE models when compared with the two types of simple BPE models. Therefore, the SCBD effect on crystallinity of the complex BPE models was much weaker than on that of the simple BPE models. Nevertheless, the critical branch content is independent of branch length, also the different MSL differences.
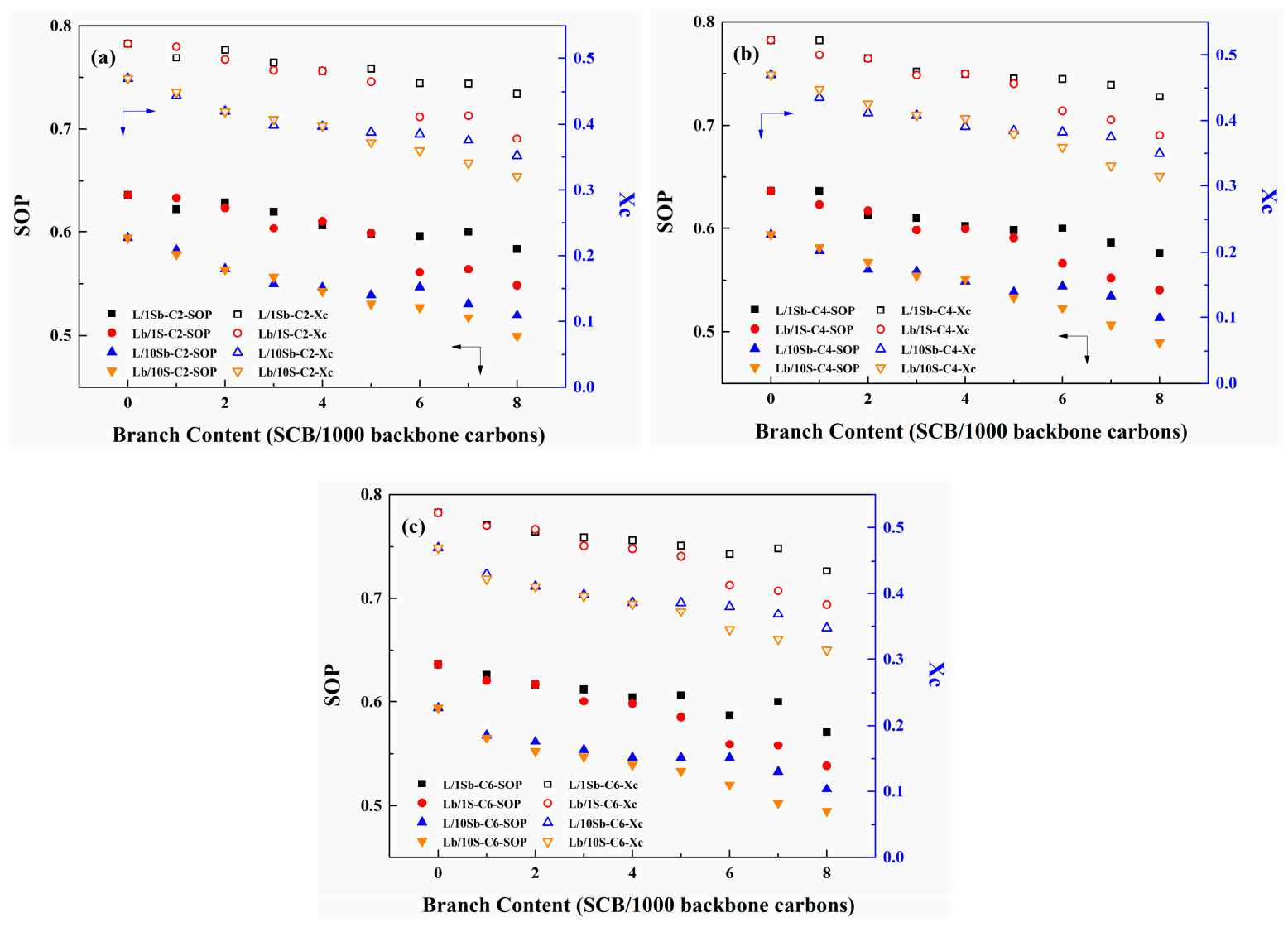

Figure 8. SCBD effect on the $\mathrm{X}_{\mathrm{c}}$ and site order parameter (SOP) of the complex BPE models and simple BPE models with (a) ethyl branches, (b) butyl branches and (c) hexyl branches. Reprinted the data for the simple BPE models with permission from Ref. [27]. Copyright 2018 Elsevier Ltd. 
The branch length dependence of $X_{c}$ and SOP for the two kinds of complex BPE models are depicted in Figure S5 in the supplementary material. Obviously, the $X_{c}$ and SOP of both the two kinds of complex BPE models are insensitive to branch length. In our previous works, the $X_{c}$ and SOP of simple BPE models and single PE model chain are also independent of branch length $[25,27]$. Wagener and co-workers discovered that the crystallinity of PE with branches evenly incorporated in each 21st carbon and 39th carbon were insensitive to branch length [34,37]. The effects of branch length on the crystallization kinetics of some ethylene copolymers were also invisible $[29,59,60]$. Choi et al. also reported that the order parameter of precisely branched polyethylene was not influenced by branch length at low branch content ( $<30 \mathrm{SCB} / 1000 \mathrm{C})$ [46]. Hence, the crystallization kinetics of BPE models, including the complex BPE models and the simple BPE models, are independent of branch length.

Figure 9 shows the final morphologies of ethyl branched complex and simple BPE models with different branch content. The final morphologies of all the BPE models correspond to the morphologies of the end of the simulation. Gray monomers represent the long chain, blue monomers represent the branches and the other colors monomers represent the short chains. As depicted in Figure 9, for the ethyl branched complex BPE models, the short chains are almost all trapped inside the long chain, no matter when the SCB incorporated in the long chain or in the short chains. For the butyl or hexyl branched complex BPE models, similar behaviors are also observed. This observation is verified by the calculated ICF difference between the initial morphology and the final morphology. The initial morphology of every model corresponds to the morphology at high temperature $\left(T^{*}=8.0\right)$ during the annealing process. However, this observation is very different from that of simple BPE models: the short chain lies outside the long chain when branches incorporated in the short chain (L/1Sb system), but the short chain is trapped inside the long chain when branches incorporated in the long chain (Lb/1S system) [27]. So it seems that when the MSL of the short chain is longer than about $60 \mathrm{CH}_{2}$, the short chain will be more likely to be trapped inside the long chain, as the $\mathrm{L} / 10 \mathrm{Sb}$ system shows. But when the MSL of the short chain is shorter than about $60 \mathrm{CH}_{2}$, the short chain tends to lie outside the long chain, as the L/1Sb system shows. When branches incorporated in the long chain, the short chain will tend to be trapped inside the long chain, as the Lb/10S system and the $\mathrm{Lb} / 1 \mathrm{~S}$ system show. Therefore, for the BPE models, including the simple BPE models and complex BPE models, the location of the short chain to the long chain depends on the MSL of the short chain.

The SCBD effect on the ICF differences between the initial and the final morphologies for all the complex BPE models are illustrated in Figure 10. It is clearly observed that ICF differences are positive for all the complex BPE models whenever the SCB incorporated in the long chain or in the short chains. Hence, the data indicates that after crystallization, short chains tend to get closer to the long chain, as Figure 8 shows that short chains are almost all trapped inside the long chain, so that the degree of entanglement of the models increase. This behavior is also different from that of simple BPE models: for the L/1Sb systems, ICF differences are all negative, while for the Lb/1S systems, ICF differences are positive [27]. It may also be attributed to the different MSLs of short chains between the L/10Sb systems and L/1Sb systems. For L/10Sb systems, as the MSLs of short chains are longer than $60 \mathrm{CH}_{2}$, short chains tend to be trapped inside the long chain, which then caused the increase of the degree of entanglement of the L/10Sb systems. But for L/1Sb systems, when the MSLs of short chain are shorter than $60 \mathrm{CH}_{2}$, the short chain will tend to lie outside the long chain, thereby the degree of entanglement of the systems will decrease. 
Lb/10S-C2-1

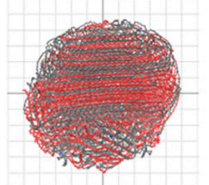

L/10Sb-C2-1

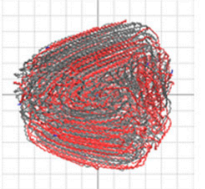

Lb/1S-C2-1

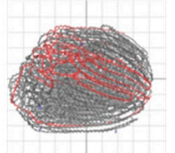

L/1Sb-C2-1

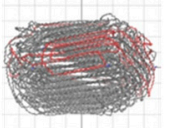

$\overline{10} \AA$
Lb/10S-C2-4

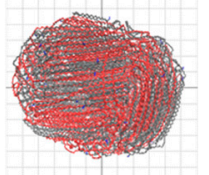

L/10Sb-C2-4

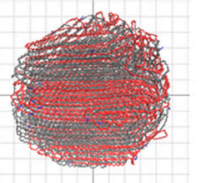

Lb/1S-C2-4

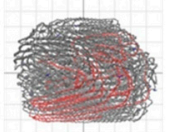

L/1Sb-C2-4

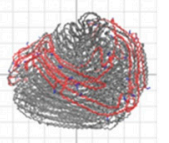

Lb/10S-C2-8

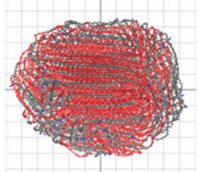

L/10Sb-C2-8

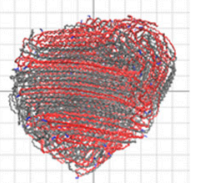

Lb/1S-C2-8

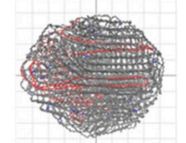

L/1Sb-C2-8

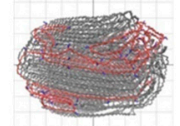

Figure 9. Final morphologies of ethyl branched BPE models. Final morphologies of all models correspond to morphologies of the end of the simulation. Gray monomers represent the long chain, blue monomers represent the branches, and red monomers represent the short chains. Reprinted the final morphologies of the simple BPE models with permission from Ref. [27]. Copyright 2018 Elsevier Ltd.

\subsection{Tie Chains}

Next, we turn our attention to reveal the SCB effect on the tie chain formation process of BPE models. Figure 11 shows the SCBD effect on the tie chains concentration for the complex BPE models and simple BPE models with different branch length. The tie chains concentration is defined as the ratio of atoms in the tie chains to the total carbons of the system [27]. Comparing the Lb/10S system and the $\mathrm{Lb} / 1 \mathrm{~S}$ system, the tie chains concentration of the $\mathrm{Lb} / 10 \mathrm{~S}$ system is higher than that of the $\mathrm{Lb} / 1 \mathrm{~S}$ system. The differences in the tie chains concentration between these two systems decreased with the increasing branch content. This may also be attributed to the lower MSL of the Lb/10S system as compared to that of the Lb/1S system, and the MSL differences between these two systems decreased with the increasing branch content, as shown in Table S1 in the supplementary material. Therefore, the tie chains concentration depends on the MSL of the system. The tie chains concentration increased with the decrease of MSL of the system. However, the tie chains concentration of the L/10Sb system is higher than that of the L/1Sb system despite the fact that the MSL of the L/10Sb system is longer than that of $\mathrm{L} / 1 \mathrm{Sb}$ system. This may be also due to the more nuclei formed in the L/10Sb system when compared with that formed in the L/1Sb system, as shown in Figure S4 in the supplementary material, so more tie chains will form in the L/10Sb system.

The tie chains concentration increased with the increasing branch content both for the two kinds of complex BPE models. This may be due to the decreased crystalline and amorphous thicknesses as branch content increased, and so that more tie chains will form [27,61]. When branch content increased to about $6 \mathrm{SCB} / 1000 \mathrm{C}$, the increase of the tie chains concentration became slow. This observation is in agreement with the result of simple BPE models [27]. Huang and Brown also found such a critical branch content for tie chain fraction at about $6 \mathrm{SCB} / 1000 \mathrm{C}$ [62]. According to the simulation work of Moyassari et al., this critical branch content is about 2.8 SCB/1000C [61]. 

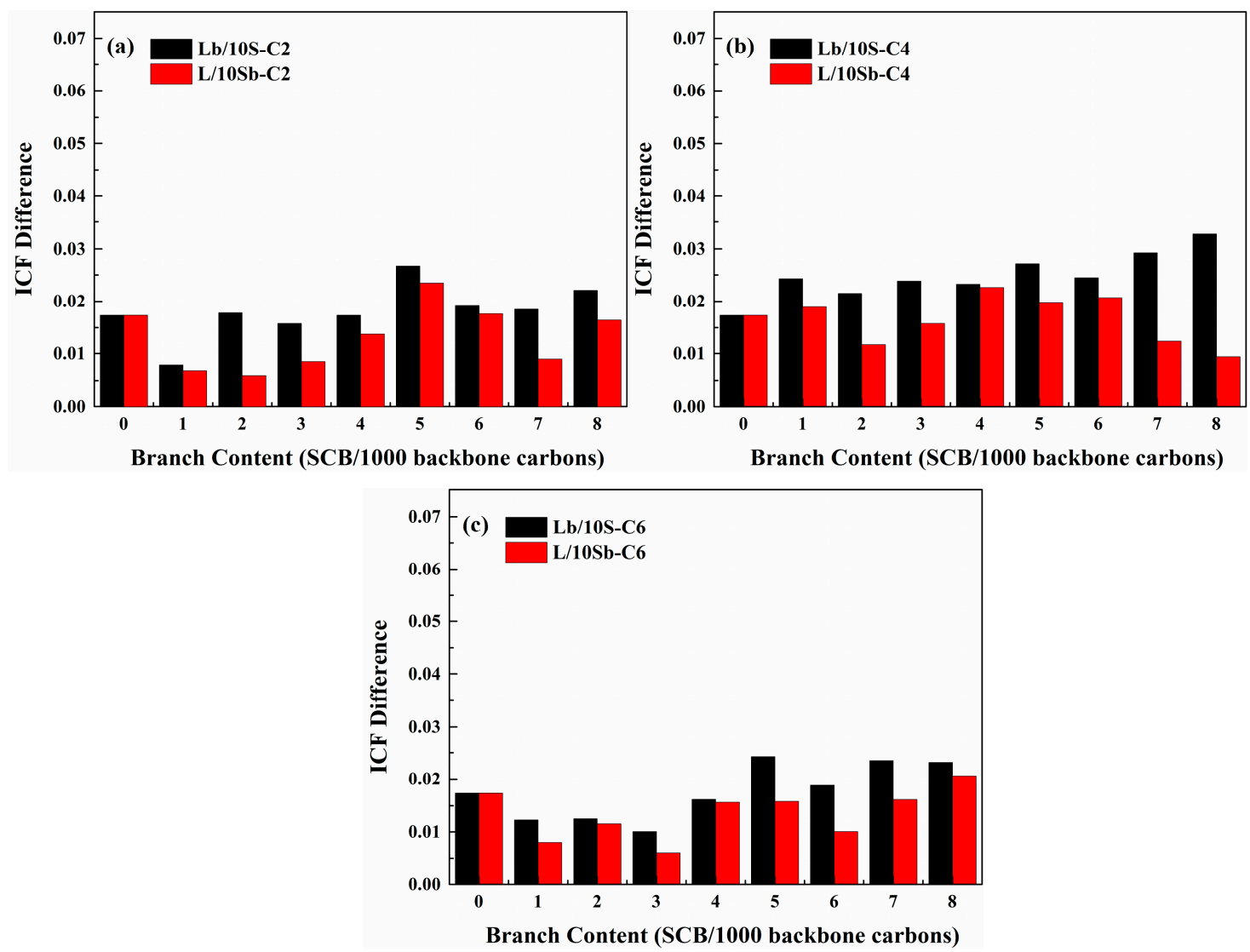

Figure 10. SCBD effect on the interchain contact fraction (ICF) difference (between the initial morphology and the final morphology) for the complex BPE models with (a) ethyl branches, (b) butyl branches and (c) hexyl branches.

Comparing the two types of complex BPE models, it is clearly observed that the tie chains concentration of $\mathrm{Lb} / 10 \mathrm{~S}$ system is higher than that of $\mathrm{L} / 10 \mathrm{Sb}$ system. For simple BPE models, the same phenomenon was observed [27]. Krishnaswamy et al. inferred that blends with short-chain branching (SCB) incorporated in the longer chains show outstanding mechanical properties which may result from the higher tie chains concentration of these blends [48]. Therefore, BPE models with SCBs incorporated in the long chain can form more tie chains in comparison with the case of SCBs incorporated in the short chain for all the BPE models. Furthermore, it is intriguing to find that the differences in the tie chains concentrations between Lb/10S systems and L/10Sb systems are much lower than those between $\mathrm{Lb} / 1 \mathrm{~S}$ systems and L/1Sb systems. This may also result from the comparable MSL between the two types of complex BPE models, but very different MSL between the two types of simple BPE models. These results seem to accord well with the results of crystallinity for the BPE models. Hence, the SCBD effect on the tie chains concentration of the complex BPE models was much weaker than on that of the simple BPE models.

The branch length dependence of tie chains concentration for the two kinds of complex BPE models is depicted in Figure 12. As observed, for all the two kinds of complex BPE models, the tie chains concentrations are insensitive to branch length. This behavior is also consistent with that of the crystallinity of these models. For the simple BPE models, the tie chains concentration was not influenced by branch length, too [27]. The main explanation is that crystalline and amorphous thicknesses are independent of branch length when branch length is smaller than $10 \mathrm{CH}_{2}$ [25]. As a result, the tie chains concentrations for both complex BPE models and simple BPE models are insensitive to branch length. 

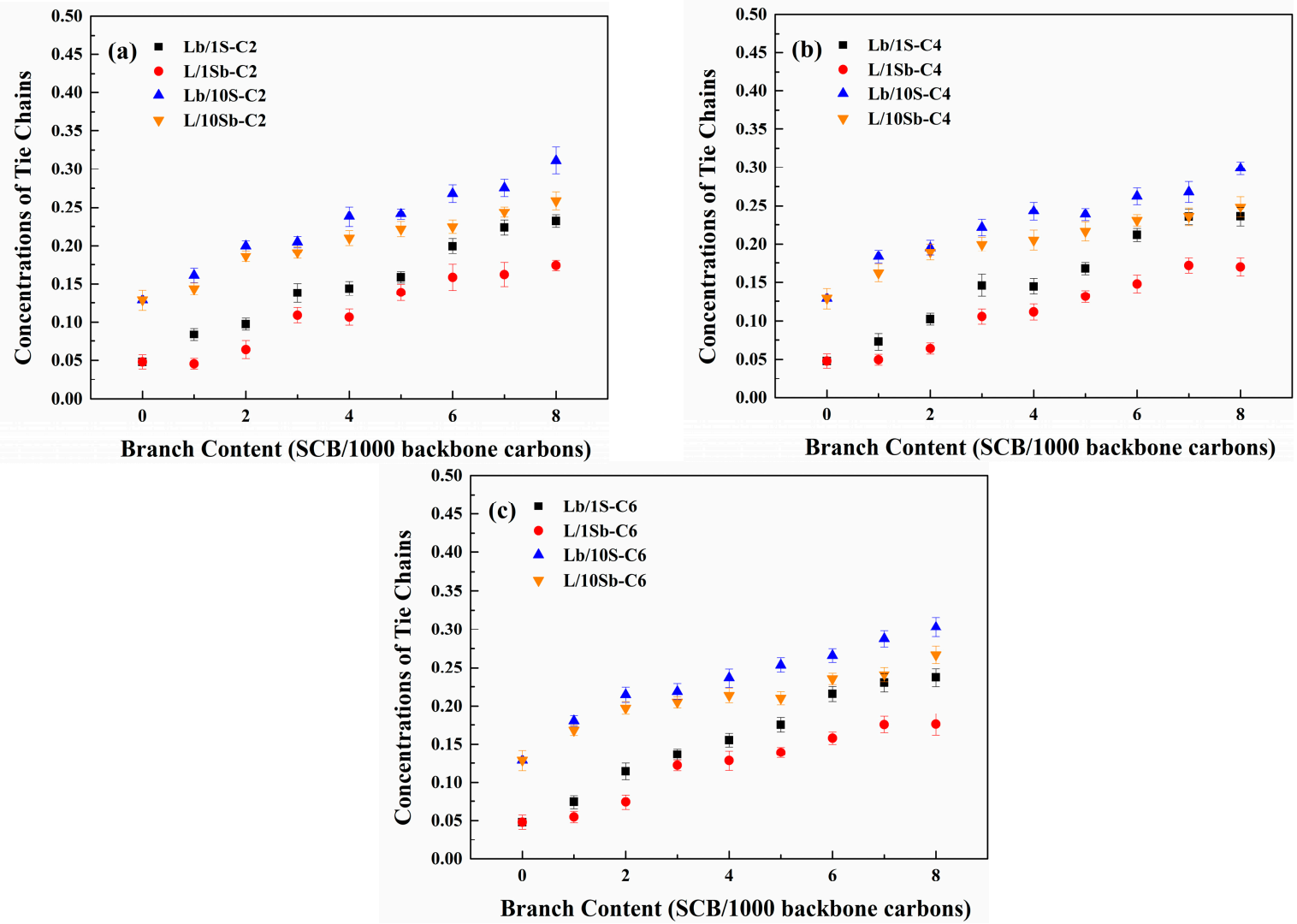

Figure 11. SCBD dependence of tie chains concentration for complex BPE models and simple BPE models with (a) ethyl branches, (b) butyl branches and (c) hexyl branches. Reprinted the data for the simple BPE models with permission from Ref. [27]. Copyright 2018 Elsevier Ltd.
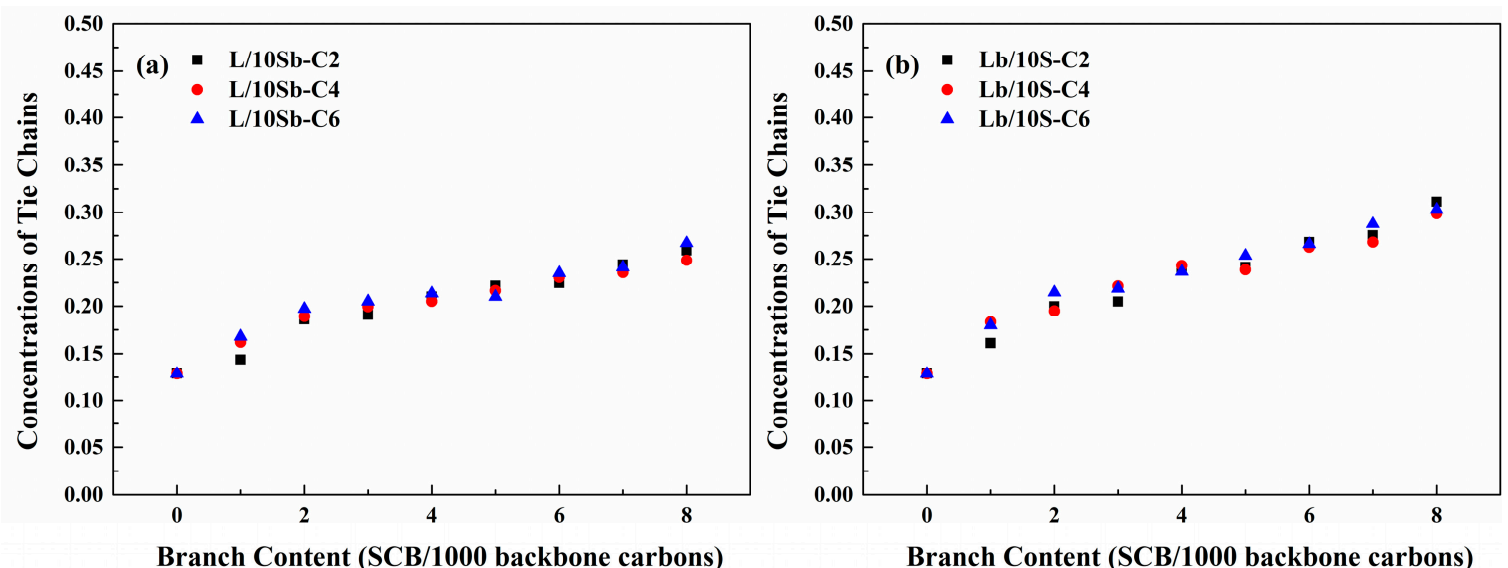

Figure 12. Branch length dependence of tie chains concentration for (a) L/10Sb systems and (b) Lb/10S systems.

\section{Conclusions}

Molecular dynamics simulation was conducted to study the molecular mechanism of SCB, especially the MSL and SCBD effect on the BPE crystallization process. The induction time of precursor formation and the initial stage of nucleation depend on the MSL of the system. It was found that $60 \mathrm{CH}_{2}$ is the critical MSL for a branched chain to nucleate. SCB incorporated in the long chain leads to a delay of induction period of precursor formation and the nucleation process when compared with that of SCB incorporated in the short chain. Additionally, these processes are further delayed when branch length increases. The crystallinity of BPE models decreased with the decrease of MSL 
of the systems. The crystallinity of BPE models with SCB incorporated in the long chain are lower than those of BPE models with SCB incorporated in the short chain when branch content exceeds $5 \mathrm{SCB} / 1000 \mathrm{C}$. This critical branch content was insensitive to branch length. The location of short chain to the long chain is determined by the MSL of the short chain. The tie chains concentration increased with the decrease of MSL of the system. When SCB incorporated in the long chain, the tie chains concentrations of the models are higher than those of the models with SCB incorporated in the short chain. The tie chain concentrations of the models are not influenced by branch length. The SCBD effect on crystallinity and the tie chains concentrations of the complex BPE models were much weaker than on that of simple BPE models. This simulation work clearly revealed the molecular mechanism of SCB, especially the effects of MSL and SCBD on the initial stage of nucleation, crystallization process and the tie chain formation process of the complex BPE models, which are similar to the normal industrial BPEs as the weight ratio of the long PE chain to the short PE chain in the BPE models is about 1:1. Further investigations of SCB effects on BPE models with another bimodal MWD are still in progress.

Supplementary Materials: The following are available online at http://www.mdpi.com/2073-4360/11/11/1840/s1, Figure S1: Box size dependence of crystallinity $\left(X_{c}\right)$ for HDPE model in Table 1 in the manuscript. $l_{\mathrm{e}}^{*}$ is the normalized distance from the end of the polymer chain to the closest edge of the box.; Figure S2. Branch length dependence of induction time $\left(t_{\mathrm{p}}^{*}\right)$ for (a) L/1Sb systems and; Figure S3. Crystallization curves of different branch content for (a) L/10Sb-C2, (b) Lb/10S-C2, (c) L/10Sb-C4, (d) Lb/10S-C4, (e) L/10Sb-C6, (f) Lb/10S-C6 systems; Figure S4. Number of nuclei of the ethyl branched complex BPE model chains and simple BPE model chains at the end of the simulation; Figure S5. Branch length dependence of SOP and $X_{c}$ for (a) L/10Sb systems and (b) Lb/10S systems; Table S1: Methylene sequence length (MSL) of the complex BPE model chains and the simple BPE model chains.

Author Contributions: Conceptualization, Y.H., X.H. and B.L.; methodology, Y.H. and X.H.; software, Y.H., X.H., Y.S. and Z.L.; validation, Y.H. and X.H.; formal analysis, Y.H.; investigation, Y.H.; resources, X.H. and B.L.; data curation, Y.H.; writing—original draft preparation, Y.H.; writing—review and editing, Y.H. and X.H.; supervision, X.H. and B.L.; project administration, X.H; funding acquisition, X.H. and B.L.

Funding: This research was funded by the National Natural Science Foundation of China, grant number 51573048.

Conflicts of Interest: The authors declare no conflict of interest.

\section{Abbreviations}

$\begin{array}{ll}\text { SCB } & \text { Short-chain branching } \\ \text { MSL } & \text { Methylene sequence length } \\ \text { SCBD } & \text { Short-chain branching distribution } \\ \text { BPE } & \text { Bimodal polyethylene } \\ \text { PE } & \text { Polyethylene } \\ \text { MWD } & \text { Molecular weight distribution } \\ \text { MD } & \text { Molecular dynamics } \\ \text { ADMET } & \text { Acyclic diene metathesis } \\ \text { HDPE } & \text { High-density polyethylene } \\ \text { SOP } & \text { Site order parameter } \\ \text { Xc } & \text { Crystallinity } \\ \text { ICF } & \text { Interchain contact fraction } \\ t_{\mathrm{p}}{ }^{*} & \text { Induction time } \\ \text { LCP } & \text { Long-chain proportion } \\ t_{n}{ }^{*} & \text { Formation time of the first stable nucleus }\end{array}$

\section{References}

1. Hubert, L.; David, L.; Seguela, R.; Vigier, G.; Degoulet, C.; Germain, Y. Physical and mechanical properties of polyethylene for pipes in relation to molecular architecture. I. Microstructure and crystallisation kinetics. Polymer 2001, 42, 8425-8434. [CrossRef]

2. Shan, C.L.P.; Soares, J.B.P.; Penlidis, A. HDPE/LLDPE reactor blends with bimodal microstructures-Part II: Rheological properties. Polymer 2003, 44, 177-185. [CrossRef] 
3. Gupta, S.; Olson, J.D. Industrial needs in physical properties. Ind. Eng. Chem. Res. 2003, 42, 6359-6374. [CrossRef]

4. Domínguez, C.; García, R.; Aroca, M.; Carrero, A. Study of the PENT test conditions for reducing failure times in high-resistance polyethylene resins for pipe applications. Mech. Time Depend. Mater. 2012, 16, 105-115. [CrossRef]

5. Chen, K.; Tian, Z.; Luo, N.; Liu, B. Modeling and simulation of Borstar bimodal polyethylene process based on a rigorous PC-SAFT equation of state model. Ind. Eng. Chem. Res. 2014, 53, 19905-19915. [CrossRef]

6. Tian, Z.; Chen, K.; Liu, B.; Luo, N.; Du, W.; Qian, F. Short-chain branching distribution oriented model development for Borstar bimodal polyethylene process and its correlation with product performance of slow crack growth. Chem. Eng. Sci. 2015, 130, 41-55. [CrossRef]

7. Huang, Y.F.; Kao, H.L.; Ruan, J.; Su, A.C. Effects of solution status on single-crystal growth habit of Poly(L-lactide). Macromolecules 2010, 43, 7222-7227. [CrossRef]

8. Lan, Y.K.; Su, A.C. Nucleation of polymer crystals: The " $\delta$ Mystery". Macromolecules 2010, 43, 7908-7912. [CrossRef]

9. Hoffman, J.D.; Miller, R.L. Kinetic of crystallization from the melt and chain folding in polyethylene fractions revisited: Theory and experiment. Polymer 1997, 38, 3151-3212. [CrossRef]

10. Waheed, N.; Lavine, M.S.; Rutledge, G.C. Molecular simulation of crystal growth in n-eicosane. J. Chem. Phys. 2002, 116, 2301-2309. [CrossRef]

11. Hu, W.; Frenkel, D.; Mathot, V.B.F. Simulation of shish-kebab crystallite induced by a single prealigned macromolecule. Macromolecules 2002, 35, 7172-7174. [CrossRef]

12. Tashiro, K.; Sasaki, S. Structural changes in the ordering process of polymers as studied by an organized combination of the various measurement techniques. Prog. Polym. Sci. 2003, 28, 451-519. [CrossRef]

13. Yamamoto, T. Molecular dynamics modeling of polymer crystallization from the melt. Polymer 2004, 45, 1357-1364. [CrossRef]

14. Strobl, G. Crystallization and melting of bulk polymers: New observations, conclusions and a thermodynamic scheme. Prog. Polym. Sci. 2006, 31, 398-442. [CrossRef]

15. Zhang, J.; Muthukumar, M. Monte Carlo simulations of single crystals from polymer solutions. J. Chem. Phys. 2007, 126, 234904. [CrossRef] [PubMed]

16. Hobbs, J.K.; Farrance, O.E.; Kailas, L. How atomic force microscopy has contributed to our understanding of polymer crystallization. Polymer 2009, 50, 4281-4292. [CrossRef]

17. Cormia, R.L.; Price, F.P.; Turnbull, D. Kinetics of crystal nucleation in polyethylene. J. Chem. Phys. 1962, 37, 1333-1340. [CrossRef]

18. Yamamoto, T. Computer modeling of polymer crystallization-Toward computer-assisted materials' design. Polymer 2009, 50, 1975-1985. [CrossRef]

19. Anwar, M.; Schilling, T. Crystallization of polyethylene: A molecular dynamics simulation study of the nucleation and growth mechanisms. Polymer 2015, 76, 307-312. [CrossRef]

20. Zerze, H.; Mittal, J.; McHugh, A.J. Ab initio crystallization of alkanes: Structure and kinetics of nuclei formation. Macromolecules 2013, 46, 9151-9157. [CrossRef]

21. Yi, P.; Rutledge, G.C. Molecular simulation of crystal nucleation in n-octane melts. J. Chem. Phys. 2009, 131, 134902. [PubMed]

22. Yi, P.; Locker, C.R.; Rutledge, G.C. Molecular dynamics simulation of homogeneous crystal nucleation in polyethylene. Macromolecules 2013, 46, 4723-4733. [CrossRef]

23. Lan, Y.K.; Su, A.C. Primary nucleation of polyethylene: Embryogenesis from a semidilute solution. Polymer 2014, 55, 3087-3092. [CrossRef]

24. Sanmartín, S.; Ramos, J.; Vega, J.F.; Martínez-Salazar, J. Strong influence of branching on the early stage of nucleation and crystal formation of fast cooled ultralong n-alkanes as revealed by computer simulation. Eur. Polym. J. 2014, 50, 190-199. [CrossRef]

25. Gao, R.; He, X.; Shao, Y.; Hu, Y.; Zhang, H.; Liu, Z.; Liu, B. Effects of branch content and branch length on polyethylene crystallization: Molecular dynamics simulation. Macromol. Theory Simul. 2016, 25, 303-311. [CrossRef]

26. Gao, R.; He, X.; Zhang, H.; Shao, Y.; Liu, Z.; Liu, B. Molecular dynamics study of the isothermal crystallization mechanism of polyethylene chain: The combined effects of chain length with temperature. J. Mol. Model. 2016, 22, 67. [CrossRef] 
27. Hu, Y.; Shao, Y.; Liu, Z.; He, X.; Liu, B. Effect of short-chain branching on the tie chains and dynamics of bimodal polyethylene: Molecular dynamics simulation. Eur. Polym. J. 2018, 103, 312-321. [CrossRef]

28. Alamo, R.G.; Mandelkern, L. Thermodynamic and structural properties of ethylene copolymers. Macromolecules 1989, 22, 1273-1277. [CrossRef]

29. Alamo, R.G.; Viers, B.D.; Mandelkern, L. Phase structure of random ethylene copolymers: A study of counit content and molecular weight as independent variables. Macromolecules 1993, 26, 5740-5747. [CrossRef]

30. Liu, J.; Zhang, F.; He, T. Effect of branch content on the transition of crystalline structure and morphology of metallocene-catalyzed branched polyethylene. J. Mater. Sci. 2001, 36, 5345-5349. [CrossRef]

31. Smith, J.A.; Brzezinska, K.R.; Valenti, D.J.; Wagener, K.B. Precisely controlled methyl branching in polyethylene via acyclic diene metathesis (ADMET) polymerization. Macromolecules 2000, 33, 3781-3794. [CrossRef]

32. Sworen, J.C.; Smith, J.A.; Wagener, K.B.; Baugh, L.S.; Rucker, S.P. Modeling random methyl branching in ethylene/propylene copolymers using metathesis chemistry: Synthesis and thermal behavior. J. Am. Chem. Soc. 2003, 125, 2228-2240. [CrossRef] [PubMed]

33. Sworen, J.C.; Wagener, K.B. Linear low-density polyethylene containing precisely placed hexyl branches. Macromolecules 2007, 40, 4414-4423. [CrossRef]

34. Rojas, G.; Inci, B.; Wei, Y.; Wagener, K.B. Precision polyethylene: Changes in morphology as a function of alkyl branch size. J. Am. Chem. Soc. 2009, 131, 17376-17386. [CrossRef] [PubMed]

35. Inci, B.; Wagener, K.B. Decreasing the alkyl branch frequency in precision polyethylene: Pushing the limits toward longer run lengths. J. Am. Chem. Soc. 2011, 133, 11872-11875. [CrossRef]

36. Nozue, Y.; Kawashima, Y.; Seno, S.; Nagamatsu, T.; Hosoda, S.; Berda, E.B.; Rojas, G.; Baughman, T.W.; Wagener, K.B. Unusual crystallization behavior of polyethylene having precisely spaced branches. Macromolecules 2011, 44, 4030-4034. [CrossRef]

37. Inci, B.; Lieberwirth, I.; Steffen, W.; Mezger, M.; Graf, R.; Landfester, K.; Wagener, K.B. Decreasing the alkyl branch frequency in precision polyethylene: Effect of alkyl branch size on nanoscale morphology. Macromolecules 2012, 45, 3367-3376. [CrossRef]

38. Silva, L.C.D.; Graf, R.; Bowers, C.R.; Wagener, K.B. Branch-Induced heterogeneous chain motion in precision polyolefins. Macromolecules 2015, 48, 8858-8866. [CrossRef]

39. Zhang, X.; Li, Z.; Lu, Z.; Sun, C. Molecular dynamics simulation of the linear low-density polyethylene crystallization. J. Chem. Phys. 2001, 115, 3916-3922. [CrossRef]

40. Zhang, X.; Li, Z.; Lu, Z.; Sun, C. The crystallization of low-density polyethylene: A molecular dynamics simulation. Polymer 2002, 43, 3223-3227. [CrossRef]

41. Zhang, X.; Li, Z.; Lu, Z.; Sun, C. Roles of branch content and branch length in copolyethylene crystallization: Molecular dynamics simulations. Macromolecules 2002, 35, 106-111. [CrossRef]

42. Zhang, X.; Li, Z.; Yang, H.; Sun, C. Molecular dynamics simulations on crystallization of polyethylene copolymer with precisely controlled branching. Macromolecules 2004, 37, 7393-7400. [CrossRef]

43. Ramos, J.; Vega, J.F.; Sanmartín, S.; Martínez-Salazar, J. Coarse-grained simulations on the crystallization, melting and annealing processes of short chain branched polyolefins. Eur. Polym. J. 2016, 85, 478-488. [CrossRef]

44. Zhang, M.; Yuen, F.; Choi, P. Differences in the solid-state structures of single-site and Ziegler-Natta linear low-density polyethylenes as revealed by molecular dynamics simulation. Macromolecules 2006, 39, 8517-8525. [CrossRef]

45. Li, C.; Choi, P. Molecular dynamics study of the solid-state structures of linear-low-density polyethylenes with blocky branches. Macromolecules 2008, 41,7109-7114. [CrossRef]

46. Choi, P.; Wang, Q.; Vignola, E. Molecular dynamics study of the conformation and dynamics of precisely branched polyethylene. Polymer 2014, 55, 5734-5738. [CrossRef]

47. Kumar, V.; Locker, C.R.; in't Veld, P.J.; Rutledge, G.C. Effect of short chain branching on the interlamellar structure of semicrystalline polyethylene. Macromolecules 2017, 50, 1206-1214. [CrossRef]

48. Krishnaswamy, R.K.; Yang, Q.; Fernandez-Ballester, L.; Kornfield, J.A. Effect of the distribution of short-chain branches on crystallization kinetics and mechanical properties of high-density polyethylene. Macromolecules 2008, 41, 1693-1704. [CrossRef]

49. Kavassalis, T.A.; Sundararajan, P.R. A molecular dynamics study of polyethylene crystallization. Macromolecules 1993, 26, 4144-4150. [CrossRef] 
50. Lindahl, E.; Hess, B.; van der Spoel, D. GROMACS 3.0: A package for molecular simulation and trajectory analysis. J. Mol. Model. 2001, 7, 306-317. [CrossRef]

51. Mayo, S.L.; Olafson, B.D.; Goddard, W.A., III. DREIDING: A generic force field for molecular simulations. J. Phys. Chem. 1990, 94, 8897-8909. [CrossRef]

52. Yu, X.; Kong, B.; Yang, X. Molecular dynamics study on the crystallization of a cluster of polymer chains depending on the initial entanglement structure. Macromolecules 2008, 41, 6733-6740. [CrossRef]

53. Wang, S.; Kong, B.; Nies, E.; Li, X.; Yang, X. Two mechanisms of polymer chain crystallization within nanoglobule. Polymer 2013, 54, 4030-4036. [CrossRef]

54. Zhang, Z.; Yang, X. The effect of chain interpenetration on an ordering process in the early stage of polymer crystal nucleation. Polymer 2006, 47, 5213-5219. [CrossRef]

55. Mao, W.; Kong, B.; Yang, X.; Nies, E. Nascent crystallization of a growing chain on a catalyst surface: A nonequilibrium molecular dynamics simulation study. J. Phys. Chem. B 2008, 112, 6753-6761. [CrossRef]

56. Li, C.; Choi, P.; Sundararajan, P.R. Simulation of chain folding in polyethylene: A comparison of united atom and explicit hydrogen atom models. Polymer 2010, 51, 2803-2808. [CrossRef]

57. Ungar, G.; Stejny, J.; Keller, A.; Bidd, I.; Whiting, M.C. The crystallization of ultralong normal paraffins: The onset of chain folding. Science 1985, 229, 386-389. [CrossRef]

58. Flory, P.J. Theory of crystallization in copolymers. Trans. Faraday Soc. 1955, 51, 848-857. [CrossRef]

59. Alamo, R.G.; Chan, E.K.M.; Mandelkern, L.; Voigt-Martin, I.G. Influence of molecular weight on the melting and phase structure of random copolymers of ethylene. Macromolecules 1992, 25, 6381-6394. [CrossRef]

60. Wignall, G.D.; Alamo, R.G.; Ritchson, E.J.; Mandelkern, L.; Schwahn, D. SANS studies of liquid-liquid phase separation in heterogeneous and metallocene-based linear low-density polyethylenes. Macromolecules 2001, 34, 8160-8165. [CrossRef]

61. Moyassari, A.; Mostafavi, H.; Gkourmpis, T.; Hedenqvist, M.S.; Gedde, U.W.; Nilsson, F. Simulation of semi-crystalline polyethylene: Effect of short-chain branching on tie chains and trapped entanglements. Polymer 2015, 72, 177-184. [CrossRef]

62. Huang, Y.L.; Brown, N. Dependence of slow crack growth in polyethylene on butyl branch density: Morphology and theory. J. Polym. Sci. Part B Polym. Phys. 1991, 29, 129-137. [CrossRef]

(C) 2019 by the authors. Licensee MDPI, Basel, Switzerland. This article is an open access article distributed under the terms and conditions of the Creative Commons Attribution (CC BY) license (http://creativecommons.org/licenses/by/4.0/). 